\title{
Evaluation of Ecological Tourism Land Use Benefit based on the Coupling Relationship
}

\author{
Bi Lifang \\ Kunming College, Kunming, Yunnan Province 650214, P.R. China \\ Xuexu123@163.com
}

Keywords Coupling relationship, Ecological tourism, Land use; MATLAB, Simulink.

\begin{abstract}
Using coupling relationship model between green economic development theory and the land use benefit system, combined with mathematical modeling, this paper designs the global coupling degree algorithm, and represent the coupling efficiency of land use. By using MATLAB Simulink, it fits the curve in the coupling process, and the coupling curve of ecological tourism land use social efficiency and the ecology benefit is obtained. Through the analysis of the coupling result, the coupling model can effectively calculate the coupling degree of ecological benefits and social benefits, which provides a theoretical basis for the research on the evaluation of land use efficiency.
\end{abstract}

\section{Introduction}

With the accelerated development of the tourism industry, the confliction of city land use is larger. Land use widespread expands faster, land use is inefficient and the land utilization benefit is imbalance. How to improve land use benefits, particularly realizing the balanced development of social economic and environmental benefits, is an inevitable requirement for sustainable development and the construction of ecological civilization society [1, 2]. Using coupling relationship model between green economic development theory and the land use benefit system, this paper designs the coupling relationship evaluation model of ecological tourism land use, and its basic frame is shown in Figure 1.

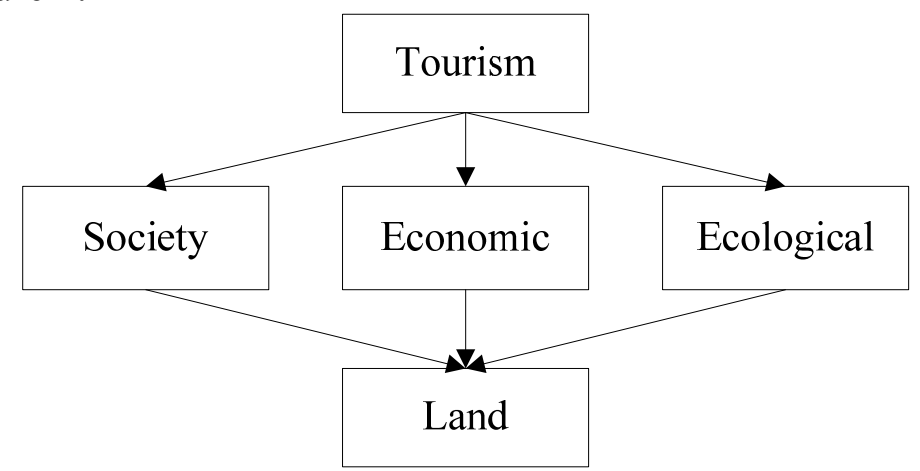

Fig. 1 The basic framework of the land use coupling relationship

Figure 1 shows the basic framework of the land use coupling relationship [3]. As shown in the figure, the land use evaluation is based on ecological tourism and green economy, establishing coupling relationship of social, economic and ecological, and it evaluates land use comprehensive benefit synthetically from three angles.

\section{Benefit Evaluation Coupling Mathematical Model and Algorithm Theoretical Basis}

Eco tourism land use efficiency is composed of social benefit, economic benefit, ecological benefit and environmental benefit, which can be summarized as the social economic benefit subsystem and the ecological environment benefit subsystem [4-6]. And they are nonlinear system with coupling relationship, as shown in Figure 2. 


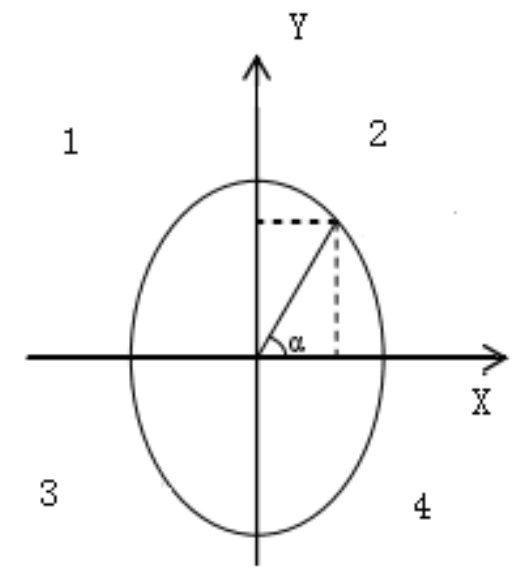

Fig. 2 Land use coupling relationship

Figure 2 shows the social economic benefit and ecological benefit coupling degree of land use [7]. In a cycle, the system can be divided into four stages, including low-grade symbiosis, harmonious development, limit development and regeneration development.

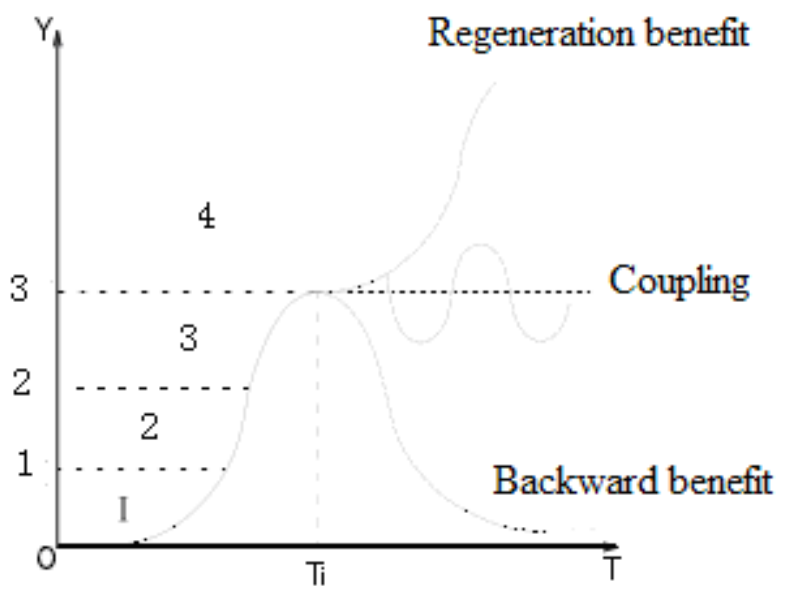

Fig. 3 Land use benefit evolution curve

As shown in Figure 3, the evolution of land use benefits coupling relation has four modes, including reviving, recycling, stagnation and retrogression, and the coupling relationship can be written in function form, as shown in the formula (1).

$$
\begin{aligned}
& Y=\frac{n \sum_{i=1}^{n} \sum_{j=1}^{n} w_{i j}\left(x_{i}-\bar{x}\right)\left(x_{j}-\bar{x}\right)}{\sum_{i=1}^{n} \sum_{j=1}^{n} w_{i j} \sum_{i=1}^{n}\left(x_{i}-\bar{x}\right)^{2}} \\
& =\frac{\sum_{i=1}^{n} \sum_{j \neq i}^{n} w_{i j}\left(x_{i}-\bar{x}\right)\left(x_{j}-\bar{x}\right)}{S^{2} \sum_{i=1}^{n} \sum_{j \neq i}^{n} w_{i j}} .
\end{aligned}
$$

Among them, $s$ is variance, the expression is as shown in formula (2).

$$
S^{2}=\frac{1}{n} \sum_{i}\left(x_{i}-\bar{x}\right)^{2} .
$$

Among them, $x$ is the average value of land use efficiency, the formula is as follows: 


$$
\bar{x}=\frac{1}{n} \sum_{i=1}^{n} x_{i}
$$

The introduction of $\bar{x}$ global coupling coefficient to express the coupling process of land use benefit, their relation is as shown in formula (4).

$$
O=\frac{(n-1) \sum_{i=1}^{n} \sum_{j=1}^{n} w_{i j}\left(x_{i}-x_{j}\right)^{2}}{2 \sum_{i=1}^{n} \sum_{j=1}^{n} w_{i j} \sum_{i=1}^{n}\left(x_{i}-\bar{x}\right)^{2}} .
$$

For the benefit coupling algorithm of ecological tourism land, it can use MATLAB Simulink toolbox to realize, through curve fitting, and evaluate the green economic benefit.

\section{Study on Evaluation of Eco Tourism Land Use Benefits based on MATLAB}

In order to verify the effectiveness and reliability of the mathematical model and the algorithm designed in section second, this paper uses MATLAB to evaluate ecological tourism land use benefit, and uses the Simulink toolbox to fit evaluation curve, finally obtains the coupling curve of ecological tourism land use benefit.

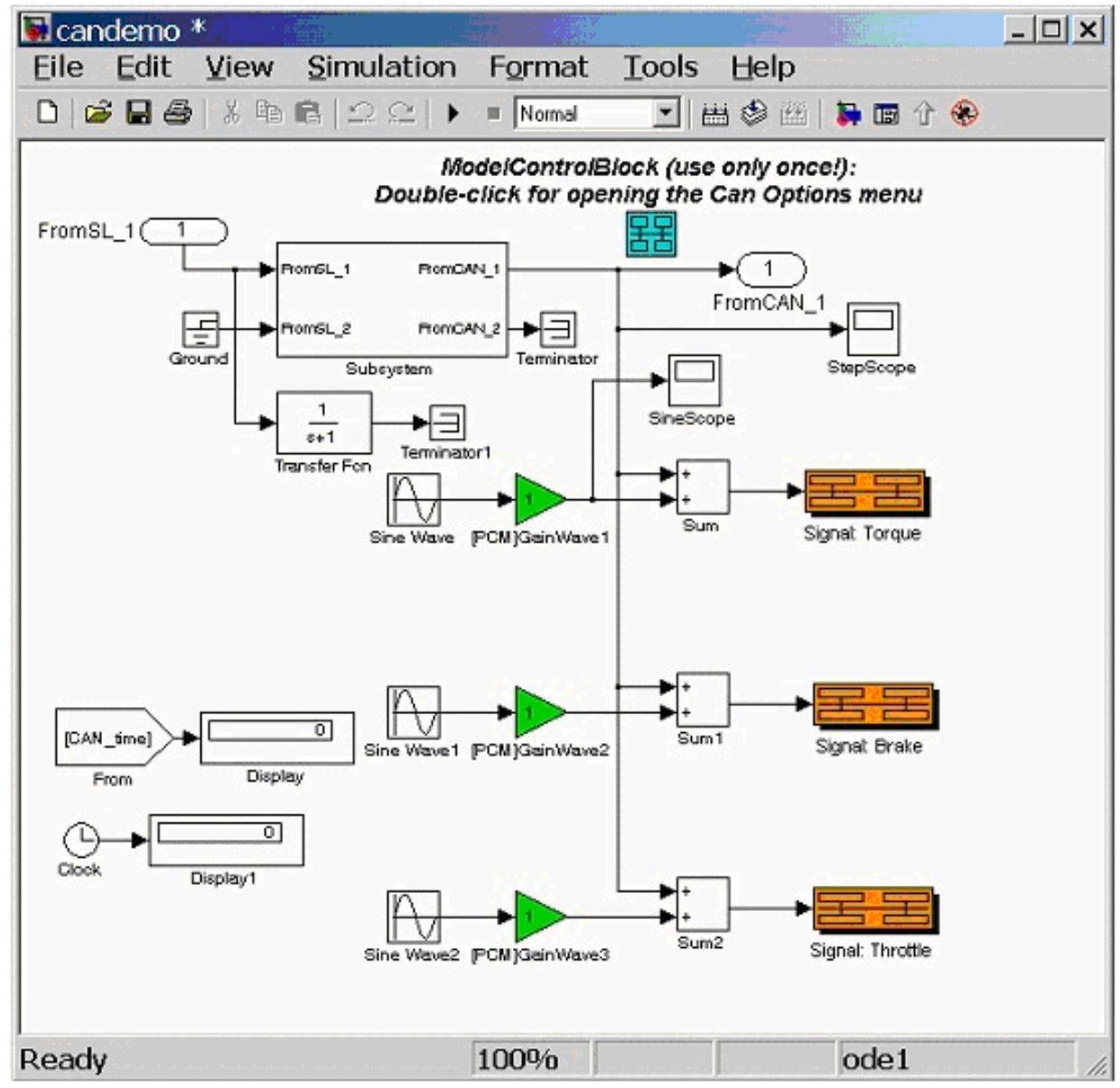

Fig. 4 Simulink toolbox

Figure 4 shows the MATLAB Simulink toolbox, which has simulation test, system control, image processing, signal processing and data statistics and other functions [8]. This function can realize benefit evaluation of ecological tourism land use practice 


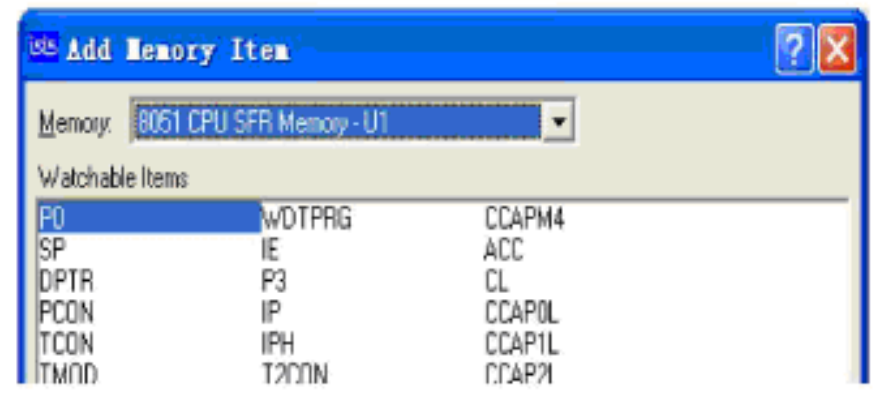

Fig. 5 The MATLAB toolbox adding inventories

In order to achieve large data process of ecological tourism land use benefit evaluation, this paper adds memory entries in the MATLAB Simulink toolbox, which not only improves the speed of calculation, but also provides more space for the storage of data [10]. Through calculating, the coupling curve of ecological tourism land use and social benefit is obtained, as shown in Figure 6.

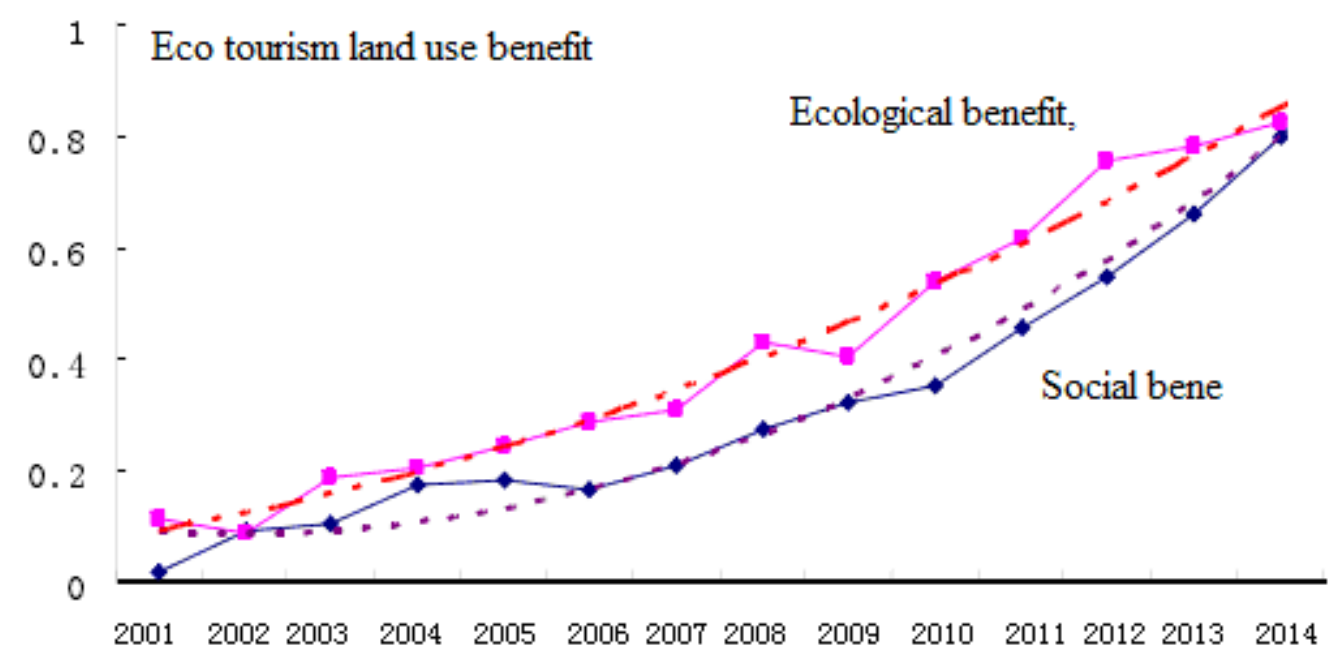

Fig. 6 Eco tourism land use efficiency curve

Figure 6 shows the eco tourism land use efficiency curve. From the chart it can be seen, the land use social benefit and ecological benefit show a rising trend year by year, but compared to the social benefit, ecological benefit has relatively slow growth rate, which is due to the ecological environment lag [11]. And the fluctuation of the ecological environment benefit is different from the social and economic benefits growth, which is mainly caused by the vulnerability and sensitivity of ecological environment subsystem.

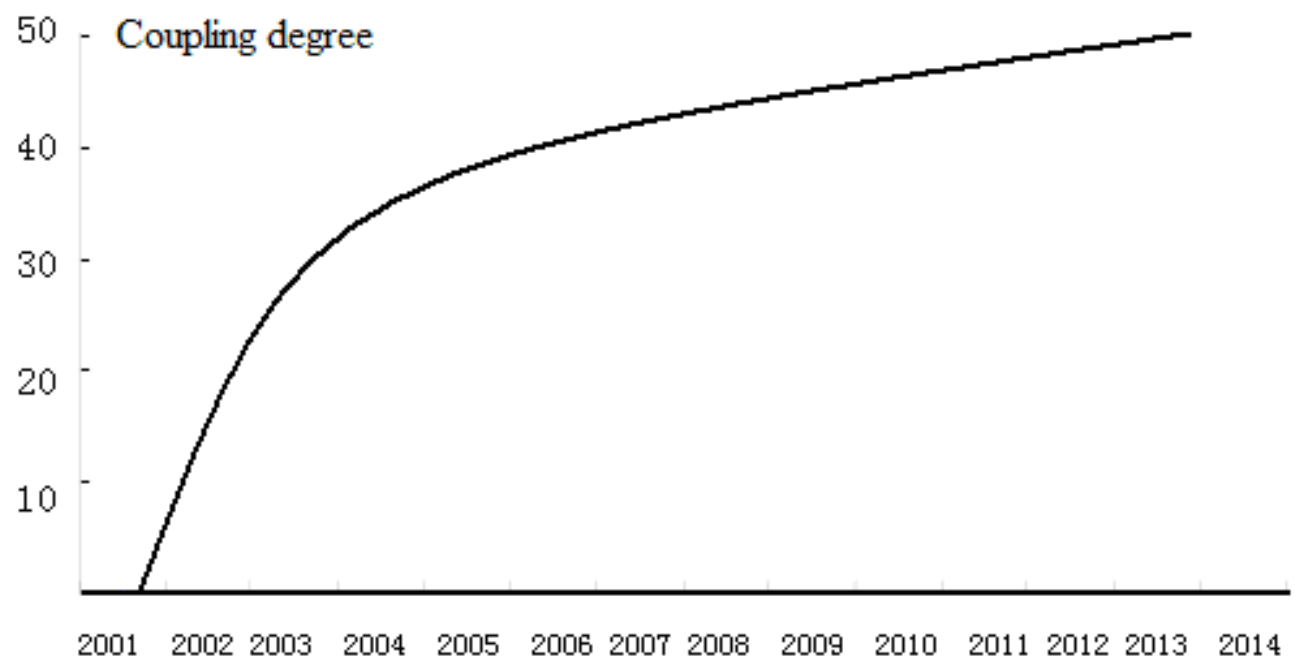

Fig. 7 Eco tourism land use benefit coupling curve

Figure 7 shows the coupling efficiency curve of eco tourism land use. On the basis of the green economy theory, this paper uses the MATLAB software to fit coupling relationship, and gets the 
result as shown in Figure 5 [12]. From the chart it can be seen, the coupling curve is from not coordination to use differentiation after intense game, which suggests that the development of social economy will still be in the cost of the ecological environment. By adjusting the feedback of green economic development, it can improve the situation and achieve the steady development of economy.

\section{Summary}

Based on the green circular economy theory, combined with the mathematical modeling, this paper designs coupling relation algorithm of land use benefits, and uses the MATLAB Simulink toolbox to fit the coupling process curve, finally obtains benefit coupling curve of ecological tourism land use. By analyzing the curve of the coupling relationship, the development of evaluation area social economy is still in the cost of the ecological environment, therefore it needs green economic development as a guide, use green economy feedback mechanism to change the current situation of land use benefit and realize the steady growth of land benefit

\section{References}

[1] K.Q. Li, Y.R. Chen, J.R. Chen. Research on the evaluation model of city land low carbon intensive use based on ANP - taking Nanjing city as an example. Economic geography, 2013, 4(2): 20-23.

[2] C.S. Song, X.H. Cui, X.L. Ke, L.M. Huang. Evolution research on the city land intensive use comprehensive benefits - using Xianning city of Hubei Province as the research. Soil and water conservation, 2013, 4(1): 12-15.

[3] H. Zhou, Y.R. Chen, Y.G. Gu. The spatial differences and driving force analysis of Chinese city land intensive use. Hubei agricultural science, 2013, 4(2): 56-59.

[4] K.H. Cao, H.M. Liang, H.P. Liu. Study on coupling relationship of Hangzhou city land use benefit. China market, 2013, 4(2): 78-80.

[5] H.F. Zhou. Construction and analysis of land utilization efficiency evaluation index. Journal of Zhejiang Shuren University, 2013, 2(2): 53-56.

[6] H.M. Liang, W.D. Liu, Y.X. Lin, Y. Liu. Land use benefit coupling model and application. Journal of Zhejiang University (agriculture and Life Science Edition), 2012, 4(2): 91-93.

[7] Y.H. Yang, A.G. Hu, N. Zhang. Human development index replace technology based on principal component analysis method. Economic research, 2013, 4(1): 23-26.

[8] Y.M. Shang, X.S. Han. Study on land use saving potential evaluation based on hierarchy analysis - based on Xingtai city. Anhui agricultural science, 2012, 4(31): 67-69.

[9] k. Yin, Y. Xiao. Research on the progress of land resources optimal allocation. Guangdong agricultural science, 2012, 4(20): 46-48.

[10]Y. Wang, R. Huang, J.H. Duan. Research on Chongqing City real estate supply and demand coordination relationship based on principal component analysis. Journal of engineering management, 2012, 4(5): 112-115.

[11] J.P. Gong, P.J. Shi, J.H. Pan. Economic benefit analysis of Lanzhou city land utilization based on the DEA method. Bulletin of soil and water conservation, 2013, 4(5): 104-106.

[12] L. Tian. The urbanization process in China. City planning, 2013, 5(2): 45-48. 